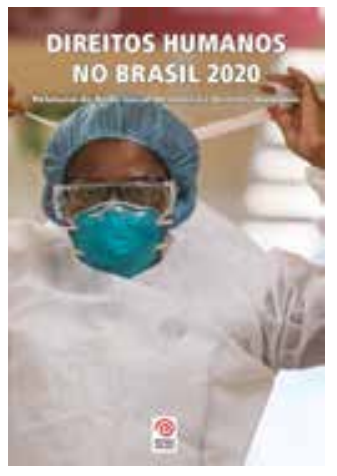

\title{
Derechos Humanos en Brasil 2020
}

\author{
Daniela Stefano e Maria Luisa Mendonça (coords. 2020). \\ Red Social por la Justicia y los Derechos Humanos \\ y Outras Expressões: São Paulo.
}

Lucas Melo Rodrigues de Sousa ${ }^{1}$

Pontifícia Universidade Católica de Minas Gerais (PUC Minas), Minas Gerais, Brasil

Organizado por la Red Social por la Justicia y los Derechos Humanos, el libro Derechos Humanos en Brasil 2020 reúne 38 artículos escritos por representantes de movimientos sociales e investigadores, enfocados en el contexto de la pandemia.

Desde el año 2000, la publicación la realiza anualmente la Red, trayendo una reflexión sobre los derechos humanos a partir de una temática que se ha destacado a lo largo del ańo.

"Siempre les pedimos [a los autores] que aborden el tema central del año según el área en la que trabajan. Este año les pedimos que hablaran de las violaciones de derechos, pero también que dieran un poco de esperanza”, explica Daniela Stefano, coorganizadora del trabajo.

Entre las reflexiones propuestas para el ańo, Daniela refuerza la secuencia de violaciones a los derechos consagrados en la Constitución de 1988, potenciada durante la pandemia. "En los últimos años, con el gobierno de Bolsonaro, la Constitución está prácticamente desgarrada. Las personas carecen cada vez más de derechos. En la pandemia, todos los sectores vulnerables pierden la protección de sus derechos. En Brasil, observamos un desprecio total por parte del gobierno de enfrentar la pandemia. Los derechos están aún más amenazados que antes".

Y agrega: "Las comunidades indígenas y quilombolas están perdiendo a sus miembros mayores y, en consecuencia, sus historias, por pura falta de política pública. Hay lugares donde las políticas públicas nunca llegaron, incluso antes de la pandemia ".

A pesar de que la edición habla de 2020, para Daniela el libro logra puntuar el escenario futuro que aún enfrentará Brasil. "Si el gobierno continúa así, el escenario descrito en el libro empeorará aún más”.

Entre los autores invitados a escribir algunos de los artículos que componen la publicación se encuentran el sociólogo y profesor Ricardo Antunes; los profesores Mariângela Graciano y Sérgio Haddad; la médica y activista Jurema Werneck, de Amnistía Internacional Brasil; Antonio Eleilson Leite, coordinador del área cultural de Ação Educativa; y Henrique Rabello de Carvalho, presidente de la Comisión de Diversidad Sexual y Género de la OAB / RJ.

Los autores señalaron los impactos de la pandemia en los derechos de la población LGBTQIA+, en el acceso al agua, la tierra y al Sistema Único de Salud (SUS),

\footnotetext{
${ }^{1}$ Especialista en Derechos Humanos. Posgraduado en Derecho Laboral y Procesos Laborales. Correo electrónico: lucasrmelo@yahoo.com.
} 
en la precariedad del mercado laboral, en el trabajo esclavo y en la vida. de pueblos indígenas y quilombolas.

"Es difícil perforar la burbuja y llegar a quienes defienden el fin de los derechos humanos o que los consideran 'derechos de bandoleros'. Sin embargo, creemos que los mensajes del libro funcionan como una herramienta de multiplicación, e incluso quienes no lean la obra, aún podrán acceder a los puntos defendidos a través de las acciones prácticas de quienes la escribieron. Desde la Declaración Universal de Derechos Humanos de la ONU, ha habido una lucha para que la gente entienda que los derechos humanos son para todos", argumenta Daniela.

En este sentido, mucho se discute sobre los derechos fundamentales de la persona humana, sin embargo tal expresión requiere que sepamos dilucidar en qué consisten estos derechos, porque son esenciales y se articulan como fundamentales, ya que no siempre están en concordancia con el concepción personal de los individuos. En general, no se sabe que garantice ciertos derechos, ni que el Estado deba respetarlos y garantizarlos.

Inicialmente, es importante entender el significado del término derechos humanos, estos son valores universales, en todos los tiempos y sociedades que permiten al individuo afirmar su condición humana y desarrollarse plenamente abarcando aspectos biológicos, psicológicos, económicos, sociales, culturales y políticos. aspectos. Son inherentes a toda colectividad y sirven para proteger a todos los hombres. Es un instrumento contra todo tipo de violencia y garantiza la preservación de la dignidad independientemente de la nacionalidad, sexo, etnia, clase social, creencia religiosa, opción política y convicción moral.

La discusión sobre la base de los derechos humanos se basa en un debate sobre la naturaleza y la razón de ser de tales derechos. Un argumento en cuanto a la razón de estos es cuidar, salvaguardar y promover la humanidad, evitando que el ser humano se convierta en una cosa. Es una fuente que pretende justificar el valor y la necesidad de estos derechos, si bien no existe un razonamiento universal y absoluto dado que la expresión puede recibir diferentes significados a lo largo del tiempo y el espacio, sino que hay una idea central basada en la dignidad de la persona. la persona humana.

Varios autores como Bobbio (1982, p. 25) reflejan que el grave problema de nuestro tiempo, con respecto a los derechos humanos, ya no es justificarlos, sino protegerlos, principalmente por los desafíos enfrentados en virtud de diferentes culturas, hábitos, convenciones y costumbres de diferentes sociedades, entre otras cosas porque una fundación sería incapaz de reflejar las múltiples nociones y esencias del hombre. Quizás sea oportuno considerar que el gran desafío de la cuestión es el carácter jurídico, considerando que el Estado debe brindar medidas para que tales derechos no sean vulnerados, los derechos humanos solo tienen efectividad definitiva cuando se experimentan, la necesidad de practicarlos ya demuestra una razón y una razón de ser.

Con el tiempo se han realizado muchos intentos para justificar la existencia de los derechos humanos y para justificarlos, Locke (1988) ya anunció la opinión de que el hombre espontáneamente tiene derecho a la vida y a la igualdad de oportunidades, tal precepto es seguido por el pensamiento de (Rousseau, 1985), que presentó la afirmación de que todos los hombres nacen libres e iguales, poseedores de derechos innatos e indispensables para su digna supervivencia, tal idea sumerge porque el hombre es un ser con sensibilidad capaz de relacionarse con sus semejantes.

El fundamento de los derechos humanos está ligado a la calidad de la dignidad de la persona humana, siendo el valor que le da humanidad al sujeto, tal idea busca garantizar la autonomía y libertad del sujeto, poseyendo todo ser humano un valor esencial. Según pa- 
labras de Kant (1980) el ser humano es considerado como un fin en sí mismo y nunca como un mero instrumento para la realización de algo. La dignidad es un valor incondicional, inconmensurable e insustituible y no tiene equivalente.

A pesar de la importancia concluyente de la justificación, parece claro que no siempre podemos hacer con seguridad lo que significa esta noción. No es fácil definirlo de manera amplia, satisfactoria e incuestionable, incluso podemos conocer el concepto de dignidad, pero no siempre somos capaces de exteriorizarlo, aunque sigue siendo confuso percibir cuando se viola la dignidad. Mantener y promover la dignidad humana es suficiente para hacer nuestra vida social menos injusta y violenta.

Durante mucho tiempo la idea de dignidad estuvo restringida a la fe divina, es decir, que todo ser humano es creado a imagen y semejanza de Dios. Aunque hoy se defiende, es mayoritariamente que la dignidad se concibe en virtud de la racionalidad del hombre. Es esta facultad la que funda la autonomía de su voluntad y la libertad que guía su acción en el mundo. El hombre es concebido como el único ser dotado de voluntad, pudiendo actuar libremente para controlar sus deseos, pero también de emoción. El hombre no sería un animal racional si no fuera afectivo, utilizamos nuestros sentimientos en beneficio de los demás y la consecución de una vida social justa y armoniosa.

Se concluye que todos los hombres están dotados de la misma dignidad, pero esto no impide que determinadas personas sean violadas. Por eso hablar de dignidad universal puede parecer una idea vaga, ya que los individuos pertenecientes a un determinado grupo social tienen protección en el éxito y otros no. El respeto, la garantía y la promoción de la dignidad es un proceso que está sujeto a retrocesos y fracasos. Por eso, tal tema debe ser discutido y presente en la vida diaria de las personas.

En consecuencia, esta comprensión se asocia a la idea de que, por tanto, los Derechos Humanos no pueden ser percibidos como un fenómeno natural, como un jusnaturalismo, un dato externo, acabado, metafísico y trascendente en relación a la existencia humana, pero sí, como un producto cultural; sobre todo, un marco cultural que nos permita percibir en los Derechos Humanos un camino hacia la dignidad.

El hombre es un ser que se puede mejorar y vencer instintos egoístas y perjudiciales para la sociedad. Por eso siempre es importante defender la educación basada en los derechos humanos, y el hombre debe estar preparado para la vida en sociedad, tal proceso puede promover valores como la solidaridad, la justicia y el respeto mutuo, desde la realización de tales valores permite la aptitud para vivir con dignidad.

\section{Referencias bibliográficas}

Bobbio, Noberto. La era de los derechos. Río de Janeiro: Campus Editora, 1992. Derechos humanos en Brasil 2020: informe de la Red Social de Justicia y Derechos Humanos - 1. Ed. - São Paulo: Otras Expresiones, 2020.

Kant, Immanuel. Fundamento metafísico de la moral. São Paulo: abril de 1980.

Locke, John. Segundo tratado de gobierno civil. São Paulo: Abril Cultural, 1978. Rousseau, Jean-Jacques. Contrato social. São Paulo: Abril Cultural, 1985. 